\title{
Nonredundant Role of Akt2 for Neuroprotection of Rod Photoreceptor Cells from Light-Induced Cell Death
}

\author{
Guiyuan Li, ${ }^{1,3}$ Robert E. Anderson, ${ }^{1,2,3}$ Hiroshi Tomita, ${ }^{6}$ Ruben Adler, ${ }^{4,5}$ Xiaochun Liu, ${ }^{4}$ Donald J. Zack ${ }^{4,5}$ and \\ Raju V. S. Rajala ${ }^{1,2,3}$ \\ Departments of ${ }^{1}$ Cell Biology and ${ }^{2}$ Ophthalmology, University of Oklahoma Health Sciences Center, Oklahoma City, Oklahoma 73104 , ${ }^{3}$ Dean McGee Eye \\ Institute, Oklahoma City, Oklahoma 73104, Departments of ${ }^{4}$ Ophthalmology and ${ }^{5}$ Neuroscience, The Johns Hopkins University School of Medicine, \\ Baltimore, Maryland 21287, and ${ }^{6}$ Division of Biofunctional Science, Tohoku University Biomedical Engineering Research Organization, Sendai 980-8575, \\ Japan
}

The Akt kinases mediate cell survival through phosphorylation and inactivation of apoptotic machinery components. Akt signaling provides a trophic signal for transformed retinal neurons in culture, but the in vivo role of Akt activity is unknown. In this study, we found that all three Akt isoforms were expressed in rod photoreceptor cells. We investigated the functional roles of Akt1 and Akt2, two of the isoforms of Akt, and their biological significance in light-induced retinal degeneration. Consistent with the hypothesis that Akt activity is important to circumvent stress-induced apoptosis, herein we report the novel finding that rod photoreceptor cells in Akt2 knock-out mice exhibited a significantly greater sensitivity to stress-induced cell death than rods in heterozygous or wild-type mice. Under similar conditions, Aktl deletion had no effect on the retina. The presence of three Akt isoforms in the retina is suggestive of a functional redundancy; however, our studies clearly demonstrate that, under stress, Akt1 and Akt 3 cannot complement the specific survival signals driven by Akt2. Furthermore, we show that Akt2 is specially activated is response to light stress. The results presented in this study provide the first direct evidence that Akt2 has a nonredundant neuroprotective role in photoreceptor survival and maintenance.

Key words: Akt/PKB; retina; photoreceptor degeneration; knock-out mice; light damage; apoptosis

\section{Introduction}

Neurons have evolved elaborate defense mechanisms that provide protection from stress-induced apoptotic cell death. The phosphoinositide 3-kinase (PI3K) pathway can be activated by a variety of signaling molecules through cell-surface receptors and can lead to activation of the serine/threonine kinase Akt, a key mediator of signal transduction processes downstream of PI3K (Hemmings, 1997; Chan et al., 1999; Kandel and Hay, 1999; Brazil and Hemmings, 2001; Scheid and Woodgett, 2001). Activated Akt phosphorylates and inactivates components of apoptotic machinery (Khwaja, 1999; Mora et al., 2001; Burgering and Kops, 2002; Sanvicens et al., 2004).

There are three isoforms of Akt (Jones et al., 1991a,b; Cheng et al., 1992; Brodbeck et al., 1999; Masure et al., 1999; Nakatani et

\footnotetext{
Received Dec. 9, 2005; revised 0ct. 18, 2006; accepted Nov. 28, 2006.

This study was supported by National Institutes of Health Grants EY04149, EY00871, EY12190, and RR17703 (R.E.A.), EY016507 (R.V.S.R.), EY04859 (R.A.), EY09769 (D.J.Z.), and Core Grant EY1765 (Johns Hopkins), Research to Prevent Blindness (Oklahoma University Health Sciences (enter and Johns Hopkins), Foundation Fighting Blindness (Oklahoma University Health Sciences Center and Johns Hopkins), the Macula Vision Foundation (Johns Hopkins), and by funds from Robert and Clarice Smith (R.A., D.J.Z.). We are grateful to Mark Dittmar (Dean A. McGee Eye Institute) for maintaining the animal colonies used in this study and to Louisa J. Williams and Linda S. Boone (Dean McGee Eye Institute) for their excellent retinal section preparations. We thank Dr. Morris Birnbaum (University of Pennsylvania, Philadelphia, PA) for his generous gift of Akt1 and Akt2 knock-out mice and Akt2 antibody, and Drs. John Ash and Yun-Zheng Le for their critical review of this manuscript.

Correspondence should be addressed to Dr. Robert E. Anderson, 608 Stanton L. Young Boulevard, Oklahoma City, OK 73104. E-mail: robert-anderson@ouhsc.edu.

DOI:10.1523/JNEUROSCI.0445-06.2007

Copyright $\odot 2007$ Society for Neuroscience $\quad$ 0270-6474/07/270203-09\$15.00/0
}

al., 1999), which are products of three separate genes located on distinct chromosomes. Akt1 and Akt2 are ubiquitously expressed, whereas Akt3 is found primarily in brain, heart, kidney, and placenta (Masure et al., 1999). Although they share $>80 \%$ amino acid sequence homology, they respond differently to insulin and growth factor stimulation (Brozinick et al., 2003). Mice lacking each of the three isoforms were generated (Chen et al., 2001; Cho et al., 2001a,b; Garofalo et al., 2003; Yang et al., 2003; Easton et al., 2005; Tschopp et al., 2005). Loss of Akt1 results in retarded growth and increased apoptosis in the thymus (Chen et al., 2001; Cho et al., 2001a). Mice lacking Akt2 have defects in glucose metabolism that ultimately lead to hyperglycemia and hyperinsulinemia (Cho et al., 2001b; Garofalo et al., 2003). Mice lacking Akt3 have a 20\% reduction in brain size (Easton et al., 2005; Tschopp et al., 2005). Because mice with deleted expression of single Akt isoforms have different phenotypes, the Akt isoforms likely have some nonredundant functions. However, because the mice are viable, it is also likely that the various isoforms provide some redundant activity as well.

Growth factor-induced activation of Akt has been shown in transformed retinal neurons (Barber et al., 2001) and mouse models of retinal degeneration (Samardzija et al., 2006). In situ hybridizations have shown that all three Akt mRNAs are present in different layers of the retina (Reiter et al., 2003). However, the functional significance of Akt isoforms in the retina is not known. In this study, we demonstrated the retinal expression of all three isoforms at the protein level. We also show that Akt2 is specifi- 
cally activated in response to stress. Using Akt1 and Akt2 knockout $(\mathrm{KO})$ mice in a model of light-induced stress, we found that deletion of Akt2, but not of Akt1, leads to a greater susceptibility of the photoreceptor cells to light-induced apoptosis compared with heterozygous (HET) or wild-type (WT) mice.

\section{Materials and Methods}

Animals. Akt1 and Akt2 heterozygous mice on a mixed genetic background of 129/C57BL/6 were obtained from Dr. Morris Birnbaum (University of Pennsylvania, Philadelphia, PA) and bred for five (Akt1) and six (Akt2) generations with BALB/c mice to generate mice with an albino background. Heterozygotes were bred to generate $A k t 1^{-/-}$and $A k t 2^{-/-}$ (KO), $A k t 1^{+/-}$and $A k t 2^{+/-}$(HET), and $A k t 1^{+/+}$and $A k t 2^{+/+}$(WT) mice from the same group of females. All mice were born and raised in 60 lux cyclic light (12 h light/dark cycle) in our animal facility and maintained under these lighting conditions until they were used in an experiment. Animal use strictly conformed to the Association for Research in Vision and Ophthalmology Statement for the Use of Animals in Ophthalmic and Vision Research and was approved by the Institutional Animal Care and Use Committees of the Oklahoma University of Health Sciences Center and the Dean A. McGee Eye Institute.

Single photoreceptor cell preparation, $c D N A$ synthesis, and PCR reaction. The cDNA synthesized from single rod photoreceptors was prepared as described by Wahlin et al. (2004). Briefly, the tissue was dissociated after papain digestion and sequential trituration with wide- and narrow-bore Pasteur pipettes. Single rod photoreceptor cells were identified and captured as described previously (Wahlin et al., 2004). cDNA synthesis and amplification were performed essentially as described by Dulac and Axel (1995) and Wahlin et al. (2004). Oligonucleotide primers used for the three Akt isoforms are as follows. The forward primers were 5' CCT GGA CTA CTT GCA CTC CGA G 3' for Akt1, 5' GAG CAT AGA TTC TTC CTC AGC ATC $3^{\prime}$ for Akt2, and 5' TAA ATT CCC CCG AAC ACT CTC TT 3' for Akt3. The reverse primers were 5' GAT CAG GCG GCG TGA TGG TGA TC $3^{\prime}$ for Akt 1, 5' GTG GTG GCA GAG GGC TGC TCA CTC $3^{\prime}$ for Akt2, and 5' TGC CGT CCA TGC CGT CGT CGT 3' for Akt3. The PCR products were 580, 249, and 289 bp for Akt1, Akt2, and Akt3, respectively. $\beta$-Phosphodiesterase ( $\beta$-PDE) forward primer was 5' GCC CTG GAG GAA GAA AAG AA 3'; the reverse primer was 5' AGG CAG AGT CCG TAT GCA GT 3'. One microliter of cDNA amplified from an individual cell was added to a $0.2 \mathrm{ml}$ PCR tube together with $24 \mu \mathrm{l}$ of a PCR supermix (Invitrogen, Carlsbad, CA) containing 200-400 nM of each oligonucleotide primer. Reactions were performed with an initial 2-min-long $94^{\circ} \mathrm{C}$ denaturation step, followed by 38 cycles of $94^{\circ} \mathrm{C}$ for $45 \mathrm{~s}, 59^{\circ} \mathrm{C}$ for $30 \mathrm{~s}$, and $72^{\circ} \mathrm{C}$ for $1.5 \mathrm{~min}$, and a final elongation step of 10 min at $72^{\circ} \mathrm{C}$. Amplification products were separated by electrophoresis on $1.0 \%$ agarose gels in $1 \times$ Tris-acetate-EDTA buffer and visualized by ethidium bromide staining.

Immunolabeling of rod outer segments and whole-mount preparations. Intact rod outer segments (ROS), some containing blebs of inner segments attached through the connecting cilium, were prepared from freshly dissected bovine retinas by gentle homogenization through a Pasteur pipette in HBSS (Sigma, St. Louis, MO) buffered with $25 \mathrm{~mm}$ HEPES, pH 7.4 (Muresan et al., 1993). Suspended cell fragments were allowed to adsorb for $3 \mathrm{~min}$ to a Vectbond-treated glass slide (Vector Laboratories, Burlingame, CA). Adhered cell fragments were fixed for 5 min in methanol at $-20^{\circ} \mathrm{C}$. Before immunostaining, slides were dipped in chloroform, dried at room temperature, and washed three times with PBS containing $0.5 \%$ Triton X-100, followed by $1 \mathrm{~h}$ of blocking by $5 \%$ BSA at room temperature. To detect the Akt isoforms in the dissociated photoreceptors, slides were coincubated with a mixture of monoclonal mouse anti-opsin (1:200) with goat anti-Aktl (1:100; Santa Cruse Biotechnology, Santa Cruz, CA), rabbit anti-Akt2 (1:100; a kind gift from Dr. Birnbaum), or rabbit-anti-Akt3 (1:100; Upstate Biotechnology, Lake Placid, NY) in PBS containing 10\% horse serum. Goat non-immune IgG served as control for Aktl, and rabbit non-immune IgG was used as control for both Akt2 and Akt3. The opsin antibody was included to clearly identify rod outer segments. Antibodies were incubated overnight at $4^{\circ} \mathrm{C}$ and then washed with PBS. For fluorescent detection, slides were incubated with a mixture of Texas Red-coupled anti-mouse and fluorescein isothiocyanate (FITC)-coupled anti-rabbit antibodies, or FITClabeled anti-goat antibody for Akt1 (Vector Laboratories), each diluted 1:1000 in the same buffer. After incubation for $1 \mathrm{~h}$ at room temperature, the slides were washed with PBS and coverslipped in 50\% glycerol in PBS. Antibody-labeled complexes were examined on a Nikon (Tokyo, Japan) Eclipse E800 microscope equipped with a digital camera, and images were captured using MetaMorph image analysis software (Universal Imaging, West Chester, PA). For quantitation, all images were captured by using conditions under which the control staining was barely visible. Identical microscope and camera settings were used for all subsequent measurements of staining, so that the visible signal reflected specific antibody binding.

Genotyping. Genotyping was performed using PCR assays of mice tail DNA, as described by Cho et al. (2001b). Genomic DNA was isolated by incubating mouse tail $(\sim 2 \mathrm{~mm})$ in $100 \mu$ l of Gittshier lysis buffer [16.6 $\mathrm{mm}\left(\mathrm{NH}_{4}\right)_{2} \mathrm{SO}_{4}, 67 \mathrm{~mm}$ Tris-HCl, $\mathrm{pH} 8.8,6.5 \mathrm{~mm} \mathrm{MgCl}_{2}, 1 \%$ basal modified Eagle, and $0.5 \%$ Triton $\mathrm{X}-100$ ] for $10 \mathrm{~min}$ at $100^{\circ} \mathrm{C}$, followed by mixing with $100 \mu \mathrm{l}$ of Gittshier lysis buffer with $5 \%$ proteinase $\mathrm{K}$ and incubating at $55^{\circ} \mathrm{C}$ for at least $2 \mathrm{~h}$. The mixture was boiled at $100^{\circ} \mathrm{C}$ for 5 min to inactivate proteinase $\mathrm{K}$. The WT mice were identified with primer A (5' TGG ACA ATC TGT CTT CAT GCC AC $\left.3^{\prime}\right)$ and B (5' AGA ATT TCT CCC TGG CAG CCA G $3^{\prime}$ ) to detect a $163 \mathrm{bp}$ PCR product. The Akt2 KO mice were identified with primer A (above) and C ( $5^{\prime}$ TAC ACT TCA TTC TCA GTA TTG TTT TGC $3^{\prime}$ ) to detect a 277 bp PCR product. All PCR reagents were from Sigma-Aldrich (St. Louis, MO); the primers were from Sigma-Genosys (St. Louis, MO).

Blood glucose. In all cases, blood samples were collected from tails cut at the tip. Mice were either fed ad libitum and samples were taken between 8:00 A.M. and 9:00 A.M., or they were fasted overnight from 5:00 P.M. to 9:00 A.M. and samples then taken. Blood glucose concentrations were measured with the TheraSense freestyle blood glucose meter according to the instruction of the manufacturer (TheraSense, Alameda, CA).

Light exposure. At 6-8 weeks of age, WT, HET, and KO mice were divided into two groups containing equal numbers of males and females. The light-stressed groups were exposed to $26 \mathrm{~h}$ of 3000 lux constant illumination as described previously (Kaldi et al., 2003). The control groups were maintained under the original lighting condition.

Functional evaluation with electroretinography. Animals were kept in total darkness overnight before their electroretinogram (Espion Visual Electrophysiology System; Diagnosys, Littleton, MA) was recorded. Mice were anesthetized with intraperitoneal injections of ketamine $(120 \mathrm{mg} /$ $\mathrm{kg}$ ) and xylazine (6 mg/kg). Pupils were dilated with $2.5 \%$ phenylephrine $\mathrm{HCl}$, and the cornea was anesthetized with topical $1 \%$ tetracaine. Electroretinographic (ERG) responses were recorded with a gold electrode placed on the cornea, a reference electrode positioned in the mouth, and a ground electrode on the tail. The duration of white-light stimulation was $4 \mathrm{~ms}$ with a 60-90 s delay between flashes with seven or eight light intensities presented in ascending order. The a-waves and b-waves were measured for each flash intensity, which began below threshold to record the b-wave sensitivity and allowed calculation of the saturated b-wave amplitude. The amplitude of the a-wave was measured from the resting baseline to the peak of the cornea-negative voltage. The amplitude of the b-wave was measured from the trough of the a-wave to the corneapositive peak. Representative ERG tracings from all three groups are shown in Figure $6 \mathrm{~A}$. A computer running commercial software (Origin 6.0; Microcal, Northampton, MA) was used to fit the data from each mouse, giving the saturated a-wave and $b$-wave amplitudes $\left(A_{\max }\right.$ and $\left.B_{\max }\right)$. The results were statistically analyzed using one-way repeatedmeasures ANOVA.

Morphologic evaluation by quantitative histology. After ERG testing, anesthetized animals were killed by asphyxiation with carbon dioxide. The eyes were enucleated, fixed, and embedded in paraffin. Fivemicrometer-thick sections of retinas were cut along the vertical meridian and stained with hematoxylin and eosin to allow an examination of the retina in the superior and inferior hemispheres. In each hemisphere, outer nuclear layer (ONL) thickness was measured at $0.24 \mathrm{~mm}$ intervals in nine defined areas, starting at the optic nerve head and extending along the vertical meridian toward the superior and inferior ora serrata (LaVail 


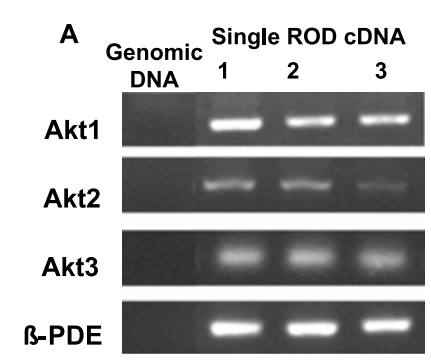

B
Opsin only
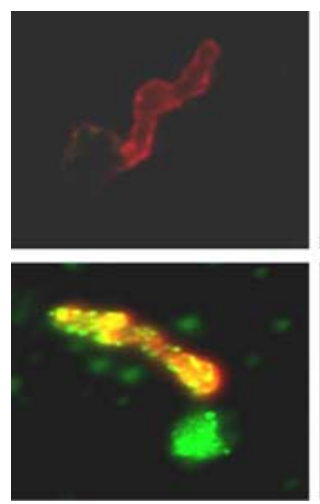

Akt2+Opsin
Akt1+Opsin
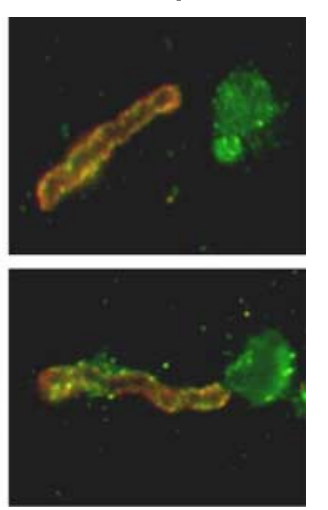

Akt3+Opsin

Figure 1. Characterization of three Akt isoforms. $A$, Single rod photoreceptor cell PCR for all three Akt isoforms and $\beta$-PDE. Mouse tail genomic DNA served as a control to rule out genomic DNA contamination, and $\beta$-PDE was used as a control for the quality of the single-cell cDNA. Results from three single rod photoreceptor cell cDNAs are presented. Akt2, Akt3, and $\beta$-PDE were found in all five preparations, and Akt1 was found in three. $\boldsymbol{B}$, Immunolocalization of Akt1, Akt2, and Akt3 in dissociated ROS (green). Bovine ROS were prepared on glass slides as described in Materials and Methods. Immunolabeling with opsin (red) was used to identify ROS. The colocalization of Akt and opsin (yellow) clearly demonstrates the presence of all three Akt isoforms in rod photoreceptors. We used normal rabbit lgG (Akt2 and Akt3) and goat lgG (Akt1) as controls for primary antibodies. All images were obtained using the same exposure condition and time, which were determined by imaging the control sections until no signal could be obtained.

et al., 1992). Mean ONL thickness was then calculated for the entire retinal section. In each experimental group, one section from each of the retinas of at least 15 mice was measured.

Photoreceptor cell apoptosis evaluation by terminal deoxynucleotidyl transferase-mediated biotinylated UTP nick end labeling assay. The terminal deoxynucleotidyl transferase-mediated biotinylated UTP nick end labeling (TUNEL) assay was used to study the apoptosis of photoreceptor cells of WT, HET, and KO mice before and immediately after $26 \mathrm{~h}$ light exposure ( $n=5$ for each group). An apoptosis detection kit (ApopTag Plus Peroxidase In Situ Apoptosis Detection; Chemicon, Temecula, CA) was used according to the instructions of the manufacturer on $5-\mu \mathrm{m}$ thick paraffin-embedded sections. At least five mice were examined in each experimental group. The number of apoptotic cells were counted and averaged.

Western blots of Akt isoforms. Retinas were dissected from 6- to 8-weekold WT, HET, and KO mice and lysed in $20 \mathrm{~mm}$ Tris-HCl, pH 7.4, containing $150 \mathrm{~mm} \mathrm{NaCl}, 1 \%(\mathrm{v} / \mathrm{v})$ Triton X-100, 5 mm EDTA, proteinase inhibitor cocktail (Roche, Indianapolis, IN), $1 \mathrm{~mm}$ phenylmethylsulfonyl fluoride, and $1 \mathrm{~mm} \mathrm{Na} \mathrm{VO}_{4}$. Thirty micrograms of retinal lysate was loaded on $10 \%$ SDS-PAGE gels, fractionated, and transferred to nitrocellulose membranes. The membrane was blocked with 5\% dry milk solution and incubated with indicated antibodies. Primary antibodies against Akt, phosphorylated-Akt (pAkt) $\left(\mathrm{Ser}^{473}\right), \mathrm{Akt1}$, Akt2, and Akt3, were detected using ECL chemiluminescence reagents (Pierce, Rockford, IL) and exposure to either X-ray film or analysis by a Kodak Image Station 4000R (Eastman Kodak, Rochester, NY).

Immunoprecipitation. Retinal lysates were solubilized for $30 \mathrm{~min}$ at $4{ }^{\circ} \mathrm{C}$ in a lysis buffer [1\% NP-40, 20 mM HEPES, pH 7.4, and 2 mM EDTA, containing phosphatase inhibitors ( $100 \mathrm{~mm}$ sodium fluoride, $10 \mathrm{~mm}$ sodium pyrophosphate, $1 \mathrm{~mm} \mathrm{NaVO}_{3}$, and $1 \mathrm{~mm}$ molybdate) and protease inhibitors (10 $\mu \mathrm{M}$ leupeptin, $10 \mu \mathrm{g} / \mathrm{ml}$ aprotinin, and $1 \mathrm{~mm}$ phenylmethylsulfonyl fluoride)]. Insoluble material was removed by centrifugation at $17,000 \times g$ for $20 \mathrm{~min}$, and the solubilized proteins were precleared by incubation with $40 \mu \mathrm{l}$ of protein A-Sepharose for $1 \mathrm{~h}$ at $4^{\circ} \mathrm{C}$ with mixing. The supernatant was incubated with anti-Akt1, anti-Akt2, and anti-Akt3 antibodies (Cell Signaling Technology, Beverly, MA) overnight at $4^{\circ} \mathrm{C}$ and subsequently with $40 \mu \mathrm{l}$ of protein A-Sepharose for $2 \mathrm{~h}$ at $4^{\circ} \mathrm{C}$. After centrifugation at $14,000 \mathrm{rpm}$ for $1 \mathrm{~min}$, immune complexes were washed three times with wash buffer [50 mM HEPES, pH 7.4, containing $118 \mathrm{~mm}$ $\mathrm{NaCl}, 100 \mathrm{~mm}$ sodium fluoride, $2 \mathrm{~mm} \mathrm{NaVO}_{3}, 0.1 \%$ (w/v) SDS, and $1 \%$ (v/v) Triton X-100]. Akt immunoprecipitates were subjected to immunoblot analysis with anti-pAkt antibody.

Statistical analysis. Results are presented as mean and SE. ONL thickness is the average of $\sim 18$ measurements made on each mouse retina at $0.24 \mathrm{~mm}$ intervals in the vertical meridian passing through the optic nerve head. One-way ANOVA with unpaired $t$ tests were used for assessing significant differences across groups for the histology and ERG results. Probability values $<0.05$ are reported as significant.

\section{Results \\ Expression of Akt isoforms in rod photoreceptor cells}

To determine which Akt isoforms are expressed in retina, we isolated RNA from five single rod photoreceptor cells from mouse and subjected it to reverse transcription (RT)-PCR using primers specific to mouse Akt1, Akt2, and Akt3. A rod photoreceptor specific gene, $\beta$-PDE, was used as a positive control. The results indicate the PCR amplification of Akt1, Akt2, and Ak3 from single rod cell PCR (Fig. $1 A$ ). To correlate our single rod cell PCR data with protein levels, we examined the expression of Akt isoforms in isolated, whole-mounted bovine photoreceptors (Muresan et al., 1993) using immunofluorescence microscopy. Photoreceptors prepared in this manner typically contain morphologically distinct ROS with inner segment blebs attached through the connecting cilium (Fig. $1 B$ ). Photoreceptor identity was confirmed by labeling of whole mounts with anti-opsin antibody. Opsin immunoreactivity was localized to the ROS with some staining in the plasma membrane of the bleb (Fig. $1 \mathrm{~B}$ ). All three Akt isoforms are expressed in both the outer and inner segments of rod photoreceptors. In the rod outer segment, the labeling was distinctly punctate in some areas (Fig. 1B). These experiments provide additional evidence that all three Akt isoforms are expressed in rod photoreceptors.

\section{Characterization of Akt 2 knock-out mice}

Akt2 heterozygous albino mice were bred to generate WT $\left(A k t 2^{+/+}\right)$, HET $\left(A k t 2^{+/-}\right)$, and KO $\left(A k t 2^{-/-}\right)$mice from the same group of females. Genotyping results are presented in Figure $2 A$, with the targeted and wild-type bands shown as 277 and $163 \mathrm{bp}$, respectively. Using cDNA from the retina of WT, HET, and KO mice, RT-PCR was performed with Akt isoform-specific primers. As predicted, the KO mice did not show Akt2 message but did show Akt1 and Akt3 genes (Fig. 2B). Western blots of retinal lysates show loss of expression of Akt2 only in the $\mathrm{KO}$ mice, with no change of Akt1 or Akt 3 in this group. Expression of Akt2 was less in the HETs than in the WT mice (Fig. 2C). The Western blot analysis shows that loss of Akt2 has no effect on the expression of either Akt1 or Akt3.

Akt2 KO mice on a DBA/1LacJ genetic background developed hyperglycemia after 2 months of age (Garofalo et al., 2003). To determine whether any effect observed in our study could be the consequence of altered levels of blood glucose, we analyzed blood glucose levels of fasting and random-fed WT, HET, and KO mice (on a BALB/c background) at 6-8 weeks of age. The results are presented in Figure 3 and showed no difference between groups. Values for fasted and random-fed animals agreed with the values 
A

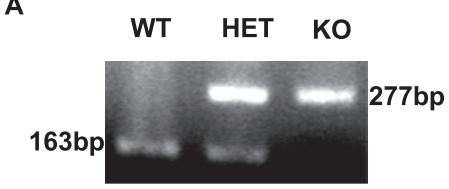

B

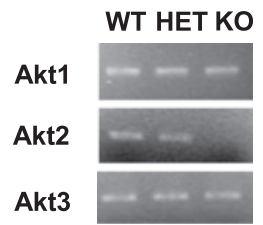

C

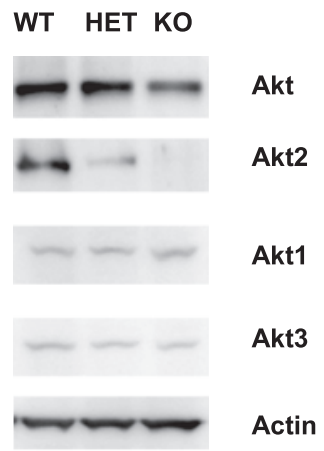

Figure 2. Akt2 expression in the retina of adult mice. $A, P C R$ genotyping of progeny: the WT band and the targeted bands are 163 and $277 \mathrm{bp}$, respectively. B, RT-PCR assays of the Akt2 KO and WT mice show that mRNA for Akt1 and Akt3, but not for Akt2, is expressed in the K0 mice, with the product sizes of 580,249, and 289 bp for Akt1, Akt2, and Akt3, respectively. C, Western blots of retina lysates $(30 \mu \mathrm{g})$ from 8-week-old WT, HET, and KO mice separated by $10 \%$ SDS-PAGE gels show the absence of Akt2 protein in the Akt2 $\mathrm{KO}$ retinas. Actin was used as a loading control.

A

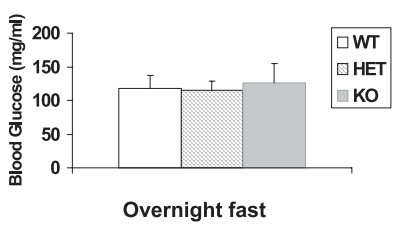

B

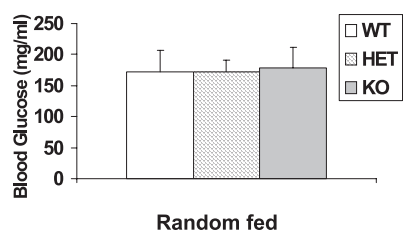

Figure 3. Blood glucose levels of fasting and random-fed mice. $A$, Blood glucose concentrations from overnight fasted mice. Values are the mean \pm SEM for WT ( $n=4$ males and 4 females), HET ( $n=5$ males and 5 females), and KO mice ( $n=5$ males and 6 females). $\boldsymbol{B}$, Blood glucose concentrations from random-fed mice. Values are the mean \pm SEM for WT, HET, and KO mice. Same number of animals were used as in the overnight fasting group. The statistical analysis used for this experiment is one-way ANOVA and unpaired $t$ test.

reported for before the onset of hyperglycemia (Cho et al., 2001b).

Light microscopic examination of the superior and inferior regions of retinas from WT, HET, and $\mathrm{KO}$ mice at 6-8 weeks of age showed no difference in retinal structure between the three groups. The retinas appeared normal and ROS appeared to be well organized (Fig. 4A). There were 11-12 rows of photoreceptor nuclei in the ONL, the number usually observed for rodents without retinal degeneration (Rapp and Smith, 1992). Quantitative analysis of the superior and inferior regions of the ONL layer of the three groups of animals showed no significant differences in the average ONL thickness measured at $0.24 \mathrm{~mm}$ intervals from the ONL to the inferior and superior ora serrata (Fig. $4 B$ ), indicating that there was no difference in rod photoreceptor viability between the three groups of mice. We further tested three older animals (4-6 months of age) in each group and detected no greater loss of nuclei in the KO group (results not shown). Thus, mice lacking Akt2 appeared to have no structural differences from WT and HET mice when maintained in relatively dim cyclic light. These results suggest that Akt2 knock-out animals do not exhibit any structural phenotype when they are maintained in dim cyclic light.

Electroretinography was used to evaluate photoreceptor function in the three groups of mice. No differences were found in the amplitude of the a-wave of the scotopic electroretinography, which measures the response of rod photoreceptor to light stimuli, or the b-wave, which measures the response of inner retinal

A

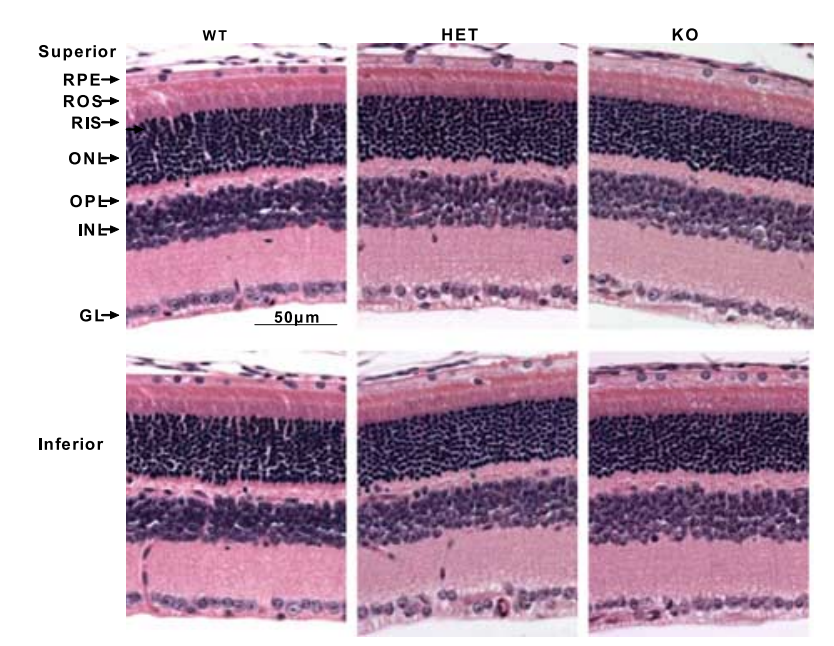

B

\section{A}

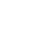

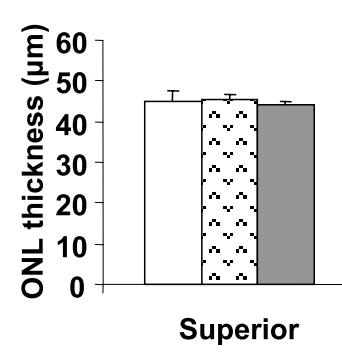

] HET

$\square \mathrm{KO}$

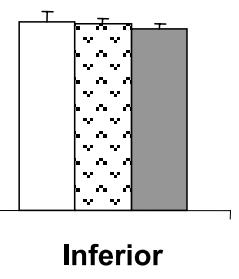

Figure 4. Morphological analysis of Akt2 $\mathrm{KO}$ mice born and raised in 60 lux cyclic light. $A$, Sections are from the superior and inferior regions of the retina of mice at $6-8$ weeks of age. Examination of 15 retinas from each group did not reveal any structural differences in any of the retinal cells at the light microscope level. GL, Ganglion cell layer; INL, inner nuclear layer; OPL, outer plexiform layer; RIS, rod inner segment; RPE, Retinal pigment epithelium. B, Quantification of morphologic changes. There were no differences in the average ONL thickness of superior and inferior regions along the vertical meridian of the eye in WT, HET, or KO mice ( $n=15$ for each group). The statistical analysis used for this experiment is one-way ANOVA and unpaired $t$ test.

Table 1. ERG measurements of Akt2 knock-out mice raised in dim cyclic light

\begin{tabular}{llll}
\hline & WT & HET & KO \\
\hline$A_{\max }$ & $457 \pm 100$ & $459 \pm 64$ & $475 \pm 85$ \\
$B_{\max }$ & $799 \pm 142$ & $769 \pm 136$ & $744 \pm 134$ \\
\hline
\end{tabular}

a-Wave and b-wave amplitudes at saturating light intensities of Akt2 knock-out mice raised in dim cyclic light were measured. The values in microvolts are the mean \pm SEM.

cells. $A_{\max }$ and $B_{\max }$, the maximal values of the $a-$ and $b$-wave amplitudes at saturating light intensities, respectively, were calculated for each group, and no significant differences were found, indicating that the absence of Akt2 did not adversely affect the function of the retinas of mice born and raised in a relatively dim cyclic light environment (Table 1). These results clearly show that Akt2 KO mice do not exhibit any functional phenotype when they are maintained in dim cyclic light.

\section{Effect of Akt2 on retinal structure after light stress}

Because Akt is a well known stress survival factor in many tissues, we tested the effect of loss of Akt 2 in a light damage model of retinal degeneration using conditions predetermined to cause significant loss of photoreceptor cells in WT albino mice. Mice were exposed to 3000 lux illumination for $26 \mathrm{~h}$. After a $5 \mathrm{~d}$ recov- 
A

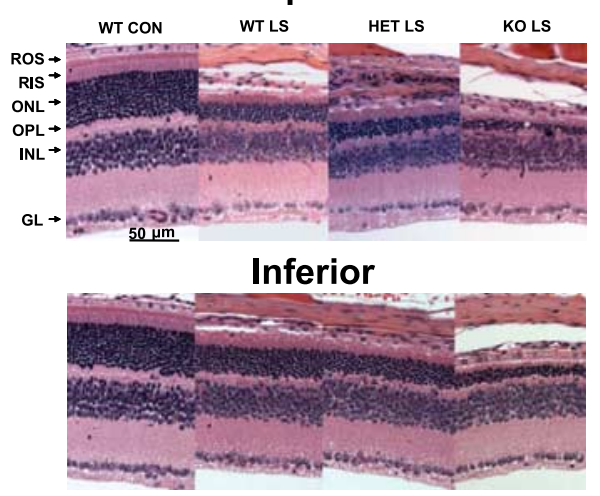

B

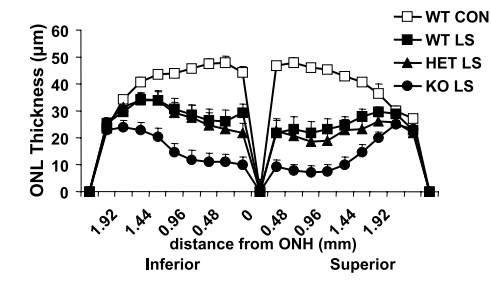

C

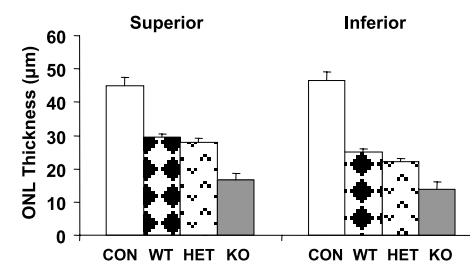

Figure 5. Morphological analysis of KO mice after light stress. $A$, Eyes of light-stressed (LS) WT, HET, and KO mice at 6 - 8 weeks of age were removed $5 \mathrm{~d}$ after $26 \mathrm{~h}$ continuous light exposure at 3000 lux and were fixed and embedded in paraffin. Representative sections from the superior and inferior retina are shown along with a WT control that was not light stressed. The only difference noted at this magnification was a reduced ONL thickness in all three light-stressed groups, with the greatest loss in nuclei appearing to occur in the K0 retinas. GL, Ganglion cell layer; INL, inner nuclear layer; OPL, outer plexiform layer; RIS, rod inner segment. $B$, Plots of ONL thickness at $0.24 \mathrm{~mm}$ intervals from the optic nerve head (ONH) along the vertical meridian in the superior and inferior regions of the retinas of light-stressed WT, HET, and KO mice and from unexposed WT mice. Values are mean \pm SEM from 15 mice in each group. C, Quantification of morphologic changes. The average $0 N L$ thickness was calculated for the superior and inferior regions of the eye in WT, HET, and KO mice. There was a significantly greater loss of rod nuclei in both hemispheres of the KO retinas compared with WT or HET retinas $(p<0.001)$. The statistical analysis used for this experiment is one-way ANOVA and unpaired $t$ test.

A
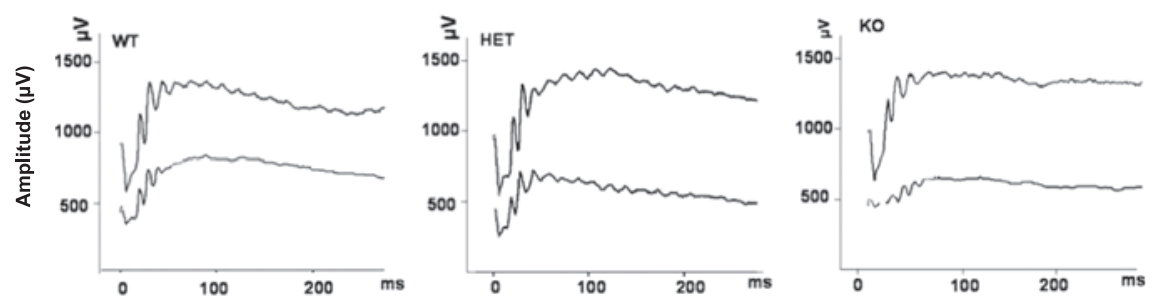

B
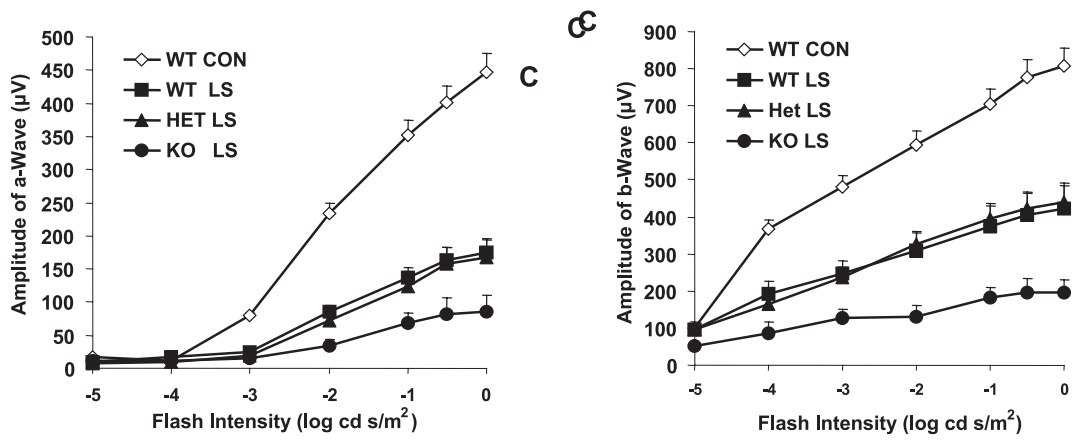

Figure 6. Functional assay of KO mice after light damage. The electroretinogram was recorded from WT controls and three light-stressed groups $5 \mathrm{~d}$ after $26 \mathrm{~h}$ continuous light exposure at 3000 lux. Values are mean \pm SEM from 15 mice in each group. $A$, Representative ERG tracing from the three groups before and after light stress. The three pairs of ERG tracing are from WT, HET, and KO groups, respectively, from left to right. $\boldsymbol{B}$, a-Wave of the electroretinogram at seven stimulation intensities. The a-wave amplitude was measured from the resting level to the peak of the cornea-negative deflection, and the $b$-wave amplitude was measured from the trough of the a-wave to the crest of the cornea-positive response. $C, b$-Wave of control and light-stressed groups. After light stress, there was a reduction in both a- and b-wave responses in all three groups. The $\mathrm{KO}$ response was significantly lower than that of the WT and HET retinas $(p<0.05)$. The statistical analysis used for this experiment is one-way ANOVA and unpaired $t$ test. ery period, we measured the extent of photoreceptor cell loss. There was a reduction in rod photoreceptors in the superior and inferior regions in the three groups (Fig. $5 A$ ), which was indicated by the loss of nuclei from the ONL. The greatest loss appeared to be in the retinas of $\mathrm{KO}$ mice. Measurement of the ONL thickness along the vertical meridian confirmed the greater loss of rod photoreceptor nuclei in the Akt2 KO mice compared with WT and HETs (Fig. 5B). Compared with nonexposed but otherwise similar experimental groups, the average ONL thickness in the superior and inferior regions of the retina of WT and HET mice was reduced by $\sim 30 \%(p<0.001)$ and of KO mice by $\sim 60 \%$ ( $p<0.001$ ). Comparing the three light-stressed groups (Fig. $5 \mathrm{C}$ ), the average ONL thickness in KO mice was $40 \%$ less than that in the HET or WT mice $(p<$ $0.01)$.

Functional evaluation of photoreceptor cells in Akt2 knock-out mice after light damage

Before we killed the mice for morphological evaluation, we tested retinal function by electroretinography $5 \mathrm{~d}$ after exposure to constant light. Figure $6 \mathrm{~A}$ shows typical wave forms from all three groups before and after light stress. Figure $6, B$ and $C$, shows the average amplitudes of a- and b-waves, respectively, in all mice tested, and are plotted as response (microvolts) versus relative flash intensity. Only WT controls are shown because there was no difference in ERG amplitudes in animals maintained in dim cyclic light among the WT, HET, and KO groups. There was a reduction in the amplitudes of both waves in all three groups as a result of light stress, with the greatest reduction occurring in the KO mice. There was no apparent difference between WT and HET mice. Histograms of $A_{\max }$ and $B_{\max }$ values (Fig. $7 A, B)$ clearly show that the sensitivity of all groups was reduced after light damage compared with control groups, but the $\mathrm{KO}$ group was more severely impaired ( $p<$ $0.05)$. These data suggest that the absence of Akt2 renders the photoreceptors of $\mathrm{KO}$ mice more sensitive to light damage than those of WT or HET mice.

\section{Effect of Akt2 deletion on apoptosis in} rod photoreceptor cells

Bright light exposure causes rod photoreceptor death by apoptosis (Organisciak et al., 1998; Krishnamoorthy et al., 1999). A number of studies have used TUNEL assays to evaluate the extent of retinal cell death after light stress (Bilton and Booker, 
A

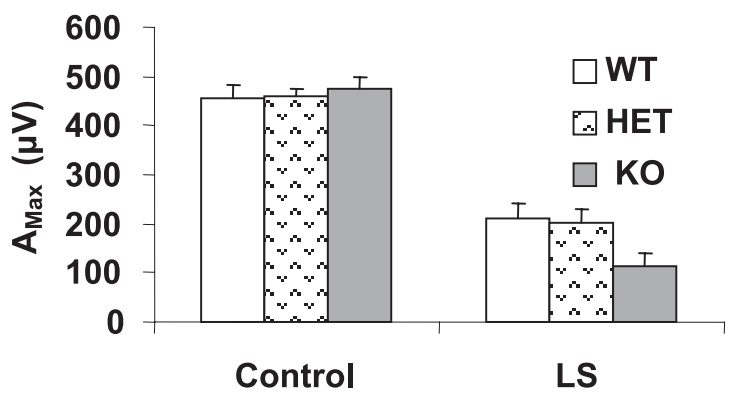

B

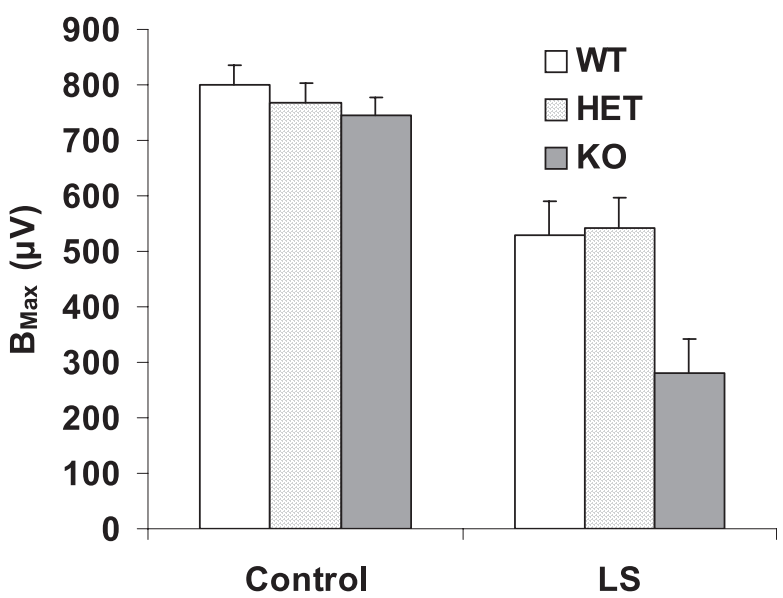

Figure 7. ERG sensitivity of WT, HET, and KO mouse retina before and after light stress. $\boldsymbol{A}$, $A_{\max }$ of WT, HET, and KO groups before and after light stress (LS). $B, B_{\max }$ of WT, HET, and KO before and after light stress. After light stress, there was a reduction in both a- and b-wave responses in all three groups. The $K 0$ response was significantly lower than that of the WT and HET retinas $(p<0.05)$. The statistical analysis used for this experiment is one-way ANOVA and unpaired $t$ test.

2003; Li et al., 2003). To examine apoptosis in each group, we performed TUNEL assays on eyes enucleated immediately after $26 \mathrm{~h}$ light exposure (Fig. 8A). No TUNEL-positive cells were seen in the normal light groups (top), whereas TUNEL-positive cells were found in retinas of all three light-exposed groups (bottom). The greatest number of TUNEL-positive cells was in the ONL of the Akt2 KO mice. The apoptotic cells were counted, and the quantitative data are presented in Figure $8 B$.

\section{Effect of Akt1 deletion on retina structure and function}

To determine the role of Akt1 on retinal structure and function, we stressed the WT, Akt1 HET, and Akt1 KO mice under conditions similar to those used for the Akt2 KO studies. Before light stress, light microscopic examination of the superior and inferior regions of retinas from WT, HET, and KO mice at 6-8 weeks of age showed no difference in retinal structure between the three groups (data not shown). Quantitative analysis of the superior and inferior regions of the ONL layer of the three groups of animals showed no significant differences in the average ONL thickness measured at $0.24 \mathrm{~mm}$ intervals from the ONL to the inferior and superior ora serrata (Fig. 9A), indicating that there was no difference in rod photoreceptor viability between the three groups of mice. To determine the effect of light stress on Akt1 knock-out mice, we exposed WT, HET, and KO mice to 3000 lux illumination for $26 \mathrm{~h}$. After a $5 \mathrm{~d}$ recovery period, we measured the extent of photoreceptor cell loss. There was a reduction in rod photoreceptors in the superior and inferior regions in the three groups (Fig. 9B), which was indicated by the loss of nuclei from the ONL. The Akt1 KO animals did not show any greater susceptibility to stress-induced loss of rod photoreceptor nuclei compared with WT and HET mice (Fig. 9B).

The electroretinogram was used to evaluate photoreceptor function in WT, HET, and KO mice. a-Wave and b-wave amplitudes at saturating light intensities, respectively, were obtained from each group, and no significant differences were found, indicating that the absence of Akt1 did not adversely affect the function of the retinas of mice born and raised in a relatively dim cyclic light environment (Fig. 10A). Exposure to light stress led to a loss of rod function (Fig. 10B), but there were no significant differences between WT, HET, and KO mice. Thus, unlike occurs in Akt2 $\mathrm{KO}$ mice, Akt1 deletion has no effect on retinal function.

\section{Light stress results in the activation of Akt2}

To determine whether light stress induced the activation of any specific isoform, we subjected albino rats to light stress for $3 \mathrm{~h}$ at 5000 lux. At the end of light exposure, rats were dark adapted and the retinas were removed $0,3,6$, and $24 \mathrm{~h}$ later. Control experiments were done on rats dark-adapted overnight. Rats were used for these studies because their retinas are larger than mice retinas and provided enough material for all three immunoprecipitation reactions to be performed on a single retinal lysate. Retinas were lysed, and an equal amount of protein was subjected to Western blot analysis with pAkt antibody. The results indicate that light stress results in the persistent activation of Akt at all time points analyzed compared with unexposed dark-adapted control (Fig. $11 \mathrm{~A}$ ). To determine whether any specific isoform was activated in response to stress, we immunoprecipitated the light-stressed retinal lysates with anti-Akt1, anti-Akt2, and anti-Akt3 antibodies, and the immune complexes were subjected to Western blot analysis with anti-pAkt antibody. There was an increased phosphorylation of Akt2 in response to stress, which was higher at all time points compared with unexposed control (Fig. 11E). Stress response did not activate Akt1, but weak activation of Akt3 was also observed.

\section{Discussion}

The central result of the present investigation is that all three Akt isoforms are expressed in rod photoreceptors, suggesting the possibility of a functional redundancy. However, our studies clearly indicate that Akt2 but not Akt1 knock-out mice exhibited a significantly greater sensitivity to stress-induced cell death as evidenced by loss of rod photoreceptor nuclei, loss of retinal function, and increased TUNEL staining in the outer nuclear layer. This is the first study that demonstrates a retinal rod photoreceptor phenotype in Akt2 $\mathrm{KO}$ mice and, to our knowledge, is the first that shows a stress-induced phenotype in Akt2 $\mathrm{KO}$ mice.

Mice with deleted expression of a single Akt isoform are viable, perhaps as the result of complementation of the lethal phenotypes by other Akt isoforms. Evidence comes from the double knock-out of Akt1 and Akt2 having more severe problems than simply the combination of those found in Akt1 null and Akt2 null mice (Peng et al., 2003). However, in photoreceptors, Akt1 appears to have no protective effect on the light-induced retinal degeneration, because our studies show that Akt1 knock-out mice are not susceptible to light-induced apoptosis. These studies are further substantiated by the specific activation of Akt2 in response to light-stress compared with Akt1 and Akt3. We also observed a weak activation of Akt 3 in response to light stress, so a 
A

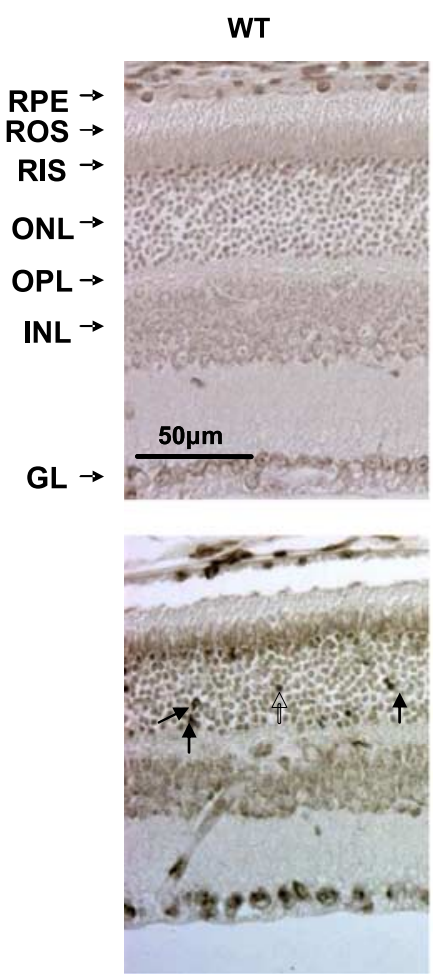

WT LS
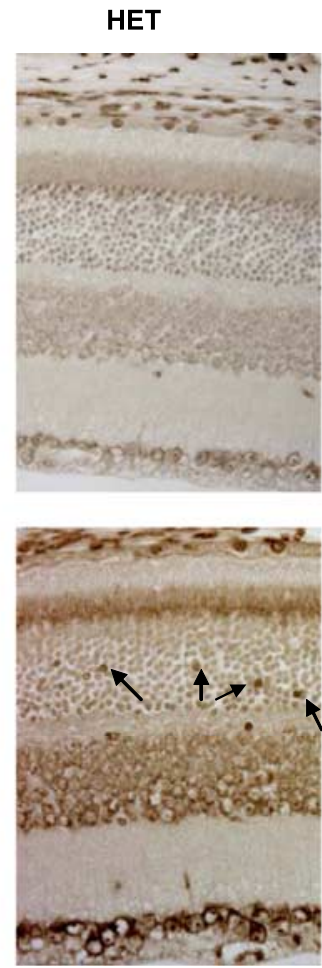

HET LS

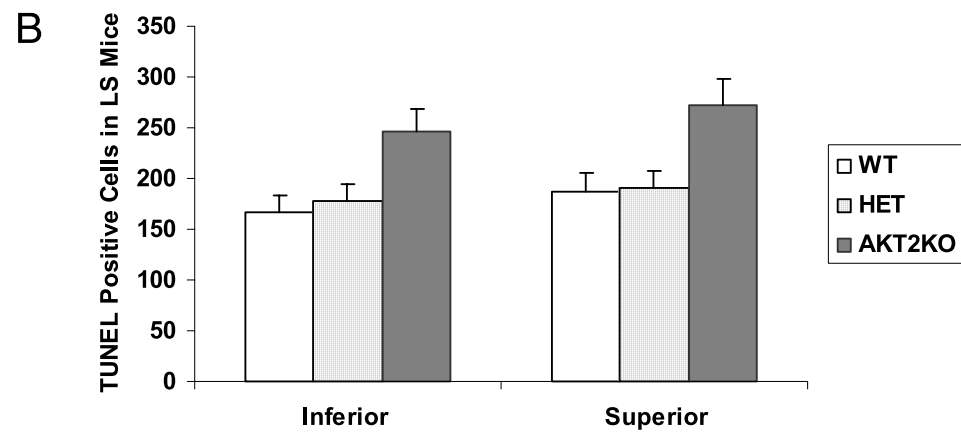

Figure 8. TUNEL assay of WT, HET, and KO mouse retinas after light stress. $\boldsymbol{A}$, Top row, Sections from the superior region of retinas from mice born and raised in 60 lux cyclic light. Bottom row, Sections from the superior region of retinas from mice, taken immediately after exposure to 3000 lux for $26 \mathrm{~h}$. These representative micrographs from five animals per experimental group show increased apoptotic nuclei in the ONL (arrows) in all three groups stressed with bright light, with the greatest number in the $K 0$ retinas. No effect of light stress $(L S)$ was seen in any other retinal cell. $B$, The number of apoptotic cells in each slide was counted and averaged. GL, Ganglion cell layer; INL, inner nuclear layer; OPL, outer plexiform layer; RIS, rod inner segment; RPE, retinal pigment epithelium.

role for Akt3 in light-induced retinal degeneration cannot be ruled out.

The stress-induced photoreceptor degeneration observed in Akt2 knock-out mice could be attributable to the unique functions of Akt2, which cannot be complemented by either Akt1 or Akt3. It is also possible that these isoforms are specifically expressed in different retinal cells in which the other isoforms are absent, which make them nonredundant to that particular cell type. Surprisingly, our study shows the expression of Akt1, Akt2, and Akt3 in photoreceptors. These observations clearly suggest that, although all of the Akt isoforms are expressed in the photoreceptors, each may have specific substrates in the retina, and substrate activation may not be complemented by one another. The observed phenotype in Akt2 knock-out mice may be attrib-
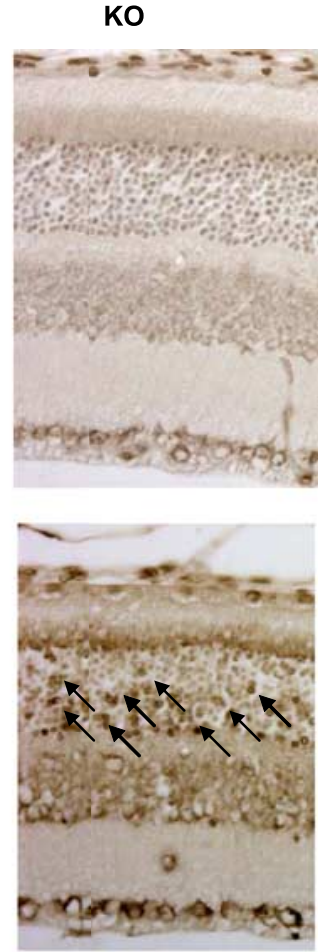

KO LS utable to the inactivation of a specific substrate(s) in the retina. Additional studies are required to identify specific substrates for individual Akt isoforms in photoreceptors.

The insulin receptor/PI3K/Akt pathway provides survival signals in many tissues (for review, see Lawlor and Alessi, 2001). Our laboratory has shown that the insulin receptor is present in the outer segments of rod photoreceptor membranes and can be activated in vivo in a lightdependent manner that is independent of insulin secretion. This leads to the binding of PI3K to the C-terminal tail of the $\beta$-subunit of the insulin receptor (IR $\beta$ ) through the N-terminal Src homology 2 domain of the p85 regulatory subunit (Rajala et al., 2002). Although the mechanism of activation of the IR $\beta$ is not known, regulation of its activity by light suggests that light-induced PI3K activity may mediate an innate self-protection mechanism. Because bright light stimulation can cause the death of rod and cone photoreceptor cells, activation of the PI3K/Akt pathway by relatively modest light levels may serve to prevent death of photoreceptors after bright light stress. We have not yet demonstrated in vivo that light stimulates the phosphorylation of Akt in ROS. However, others (Reiter et al., 2003) and we (Rajala et al., 2004) have shown that insulin promotes Akt activation in retinal explants and cultured retinal neurons. We speculate that Akt2 is activated in ROS and then moves to the inner segment to act on its downstream effector(s). Consistent with this notion is a recent finding in our laboratory that conditional deletion of BCL-XL in rod photoreceptor cells increases their susceptibility to lightinduced apoptosis (Zheng L. et al., 2006). Whether this proposed pathway of light $\rightarrow$ IR $\rightarrow$ Akt-2 might also be neuroprotective in other retinal stresses, such as mutations in genes that cause a retinal degeneration, remains to be determined.

Akt plays a major role in cell survival and acts as an anti-apoptotic agent by affecting many downstream effectors such as BAD (Bcl-2-associated death protein), FKHR (forkhead transcription factor), and caspase-3 (Khwaja, 1999; Orike et al., 2001). Akt can also exert a positive effect on nuclear factor $-\kappa \mathrm{B}(\mathrm{NF}-\kappa \mathrm{B})$ function by phosphorylation and activation of $\mathrm{I} \kappa \mathrm{B}$ kinase (Cantley, 2002), and NF- $\kappa \mathrm{B}$ can enter the nucleus to initiate transcription of anti-apoptotic factors. Kim et al. (2002) found a direct association of Akt and JIP1 [JNK (c-Jun $\mathrm{N}$-terminal protein kinase) binding protein] on a JNK pathway scaffold in primary neurons. This inhibited JIP1-mediated potentiation of JNK activity by decreasing JIP1 binding to specific JNK pathway kinases. Consistent with this view, neurons from Akt1-deficient mice exhibited higher susceptibility to kainate than WT littermates. Overexpression of Akt1 mutants that bind 


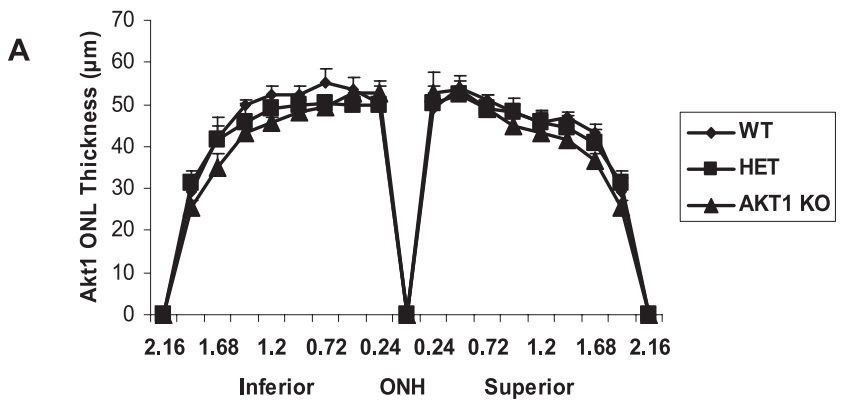

B

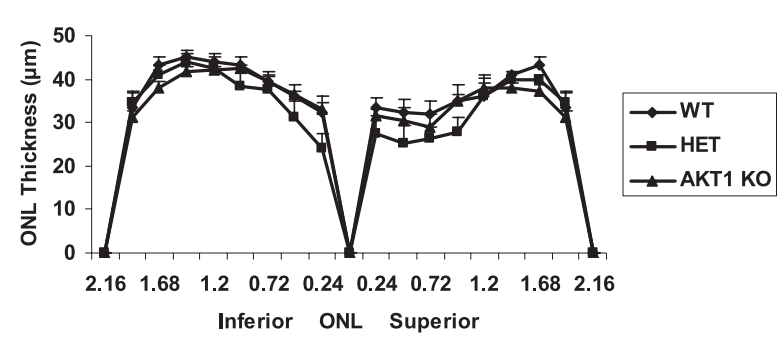

Figure 9. Quantification of morphologic changes in Akt $1 \mathrm{KO}$. A, There were no differences in the average $\mathrm{ONL}$ thickness of superior and inferior regions along the vertical meridian of the eye in WT, HET, or KO mice ( $n=15$ for each group). B, Eyes of light-stressed (LS) WT, HET, and Akt1 $\mathrm{K} 0$ mice at $6-8$ weeks of age were removed $5 \mathrm{~d}$ after $26 \mathrm{~h}$ continuous light exposure at 3000 lux and were fixed and embedded in paraffin. Plots of ONL thickness at $0.24 \mathrm{~mm}$ intervals from the optic nerve head $(\mathrm{ONH})$ along the vertical meridian in the superior and inferior regions of the retinas of light-stressed WT, HET, and KO mice. Values are mean \pm SEM from 15 mice in each group. The statistical analysis used for this experiment is one-way ANOVA and unpaired $t$ test.
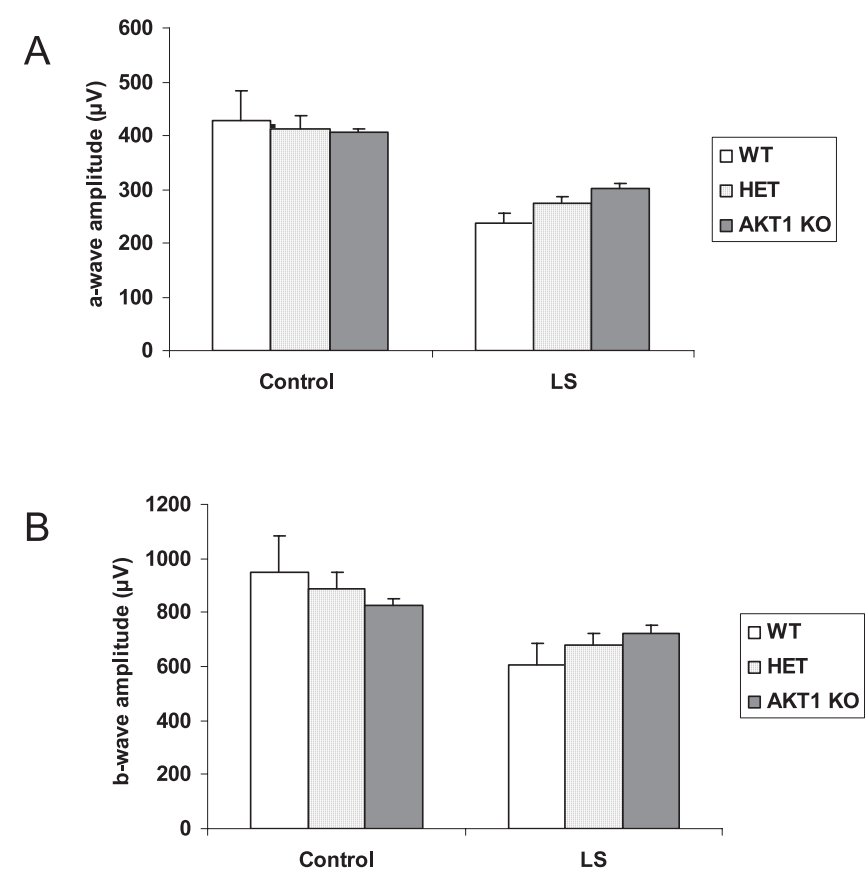

Figure 10. ERG sensitivity of WT, HET, and Akt $1 \mathrm{KO}$ mouse retina before and after light stress. The ERGs for Akt1 mice were done at the highest intensity used for Akt2 mice settings. The a-wave $(\boldsymbol{A})$ and b-wave $(\boldsymbol{B})$ amplitudes of WT, HET, and Akt1 KO mice before and after light stress were measured. After light stress, there was a reduction in both a- and b-wave responses in all three groups. There was no change in either a-wave or b-wave response in $\mathrm{KO}$ mice after light stress compared with HET. The statistical analysis used for this experiment is one-way ANOVA and unpaired $t$ test.

\section{Light Exposure 5k, 3h}
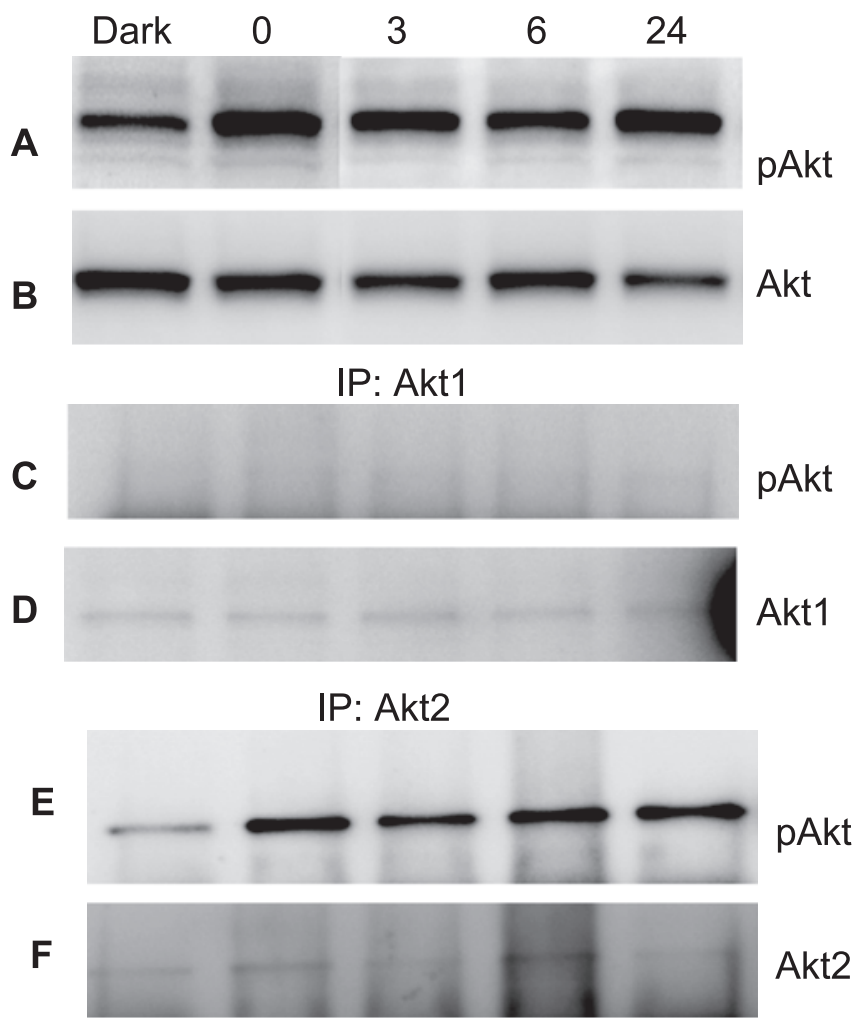

IP: Akt3

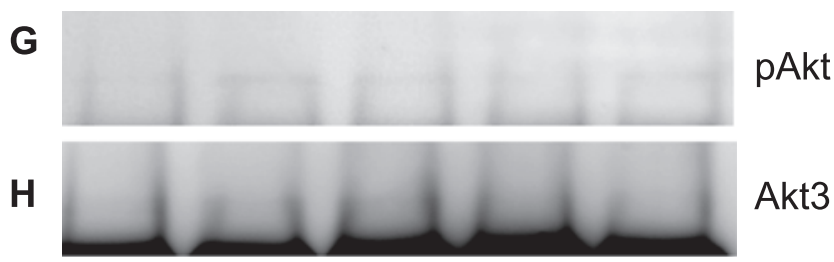

Figure 11. Activation of Akt isoforms in response to light stress. Rats were subjected to light stress for $3 \mathrm{~h}$ at 5000 lux. At the end of light exposure, rats were dark adapted and the retinas were removed $0,3,6$, and $24 \mathrm{~h}$ later. Control experiments were done on overnight dark-adapted rats. Retinas were lysed, and equal amount of protein was subjected to Western blot analysis with anti-pAkt $(\boldsymbol{A})$ and anti-Akt $(\boldsymbol{B})$ antibodies. To determine the specific isoform activation in response to stress, we immunoprecipitated (IP) the proteins from light stress samples with anti-Akt1 $(\boldsymbol{D})$, anti-Akt2 $(\boldsymbol{F})$, and anti-Akt3 $(\boldsymbol{H})$ antibodies. The immune complexes were subjected to Western blot analysis with anti-pAkt $(\boldsymbol{C}, \boldsymbol{E}, \boldsymbol{G})$ antibody.

JIP1 reduces excitotoxic apoptosis. These results suggest that Akt binding to JIP1 acts as a regulatory gate preventing the activation of JNK, which is released under conditions of excitotoxic injury (Kim et al., 2002). We are currently studying these and other downstream effectors to identify the mechanism of enhanced sensitivity of Akt2-deficient mice to acute light stress.

In summary, we have shown that albino mice deficient in Akt2 are more susceptible to light-induced apoptosis than HET or WT mice. Although all three Akt isoforms are expressed in the photoreceptors, Akt2 serves a nonredundant function. Our studies clearly suggest that the functions of Akt 2 in photoreceptor cannot be complemented by Akt1 and Akt3. Molecules or agents that can specifically activate Akt 2 could be used as novel therapeutics to protect the dying retinal cells from stress-induced retinal degeneration. 


\section{References}

Barber AJ, Nakamura M, Wolpert EB, Reiter CE, Seigel GM, Antonetti DA, Gardner TW (2001) Insulin rescues retinal neurons from apoptosis by a phosphatidylinositol 3-kinase/Akt-mediated mechanism that reduces the activation of caspase-3. J Biol Chem 276:32814-32821.

Bilton RL, Booker GW (2003) The subtle side to hypoxia inducible factor (HIFalpha) regulation. Eur J Biochem 270:791-798.

Brazil DP, Hemmings BA (2001) Ten years of protein kinase B signalling: a hard Akt to follow. Trends Biochem Sci 26:657-664.

Brodbeck D, Cron P, Hemmings BA (1999) A human protein kinase Bgamma with regulatory phosphorylation sites in the activation loop and in the C-terminal hydrophobic domain. J Biol Chem 274:9133-9136.

Brozinick Jr JT, Roberts BR, Dohm GL (2003) Defective signaling through Akt- 2 and -3 but not Akt-1 in insulin-resistant human skeletal muscle: potential role in insulin resistance. Diabetes 52:935-941.

Burgering BM, Kops GJ (2002) Cell cycle and death control: long live Forkheads. Trends Biochem Sci 27:352-360.

Cantley LC (2002) The phosphoinositide 3-kinase pathway. Science 296:1655-1657.

Chan TO, Rittenhouse SE, Tsichlis PN (1999) AKT/PKB and other D3 phosphoinositide-regulated kinases: kinase activation by phosphoinositide-dependent phosphorylation. Annu Rev Biochem 68:965-1014.

Chen WS, Xu PZ, Gottlob K, Chen ML, Sokol K, Shiyanova T, Roninson I, Weng W, Suzuki R, Tobe K, Kadowaki T, Hay N (2001) Growth retardation and increased apoptosis in mice with homozygous disruption of the Akt1 gene. Genes Dev 15:2203-2208.

Cheng JQ, Godwin AK, Bellacosa A, Taguchi T, Franke TF, Hamilton TC, Tsichlis PN, Testa JR (1992) AKT2, a putative oncogene encoding a member of a subfamily of protein-serine/threonine kinases, is amplified in human ovarian carcinomas. Proc Natl Acad Sci USA 89:9267-9271.

Cho H, Thorvaldsen JL, Chu Q, Feng F, Birnbaum MJ (2001a) Akt1/PKBalpha is required for normal growth but dispensable for maintenance of glucose homeostasis in mice. J Biol Chem 276:38349-38352.

Cho H, Mu J, Kim JK, Thorvaldsen JL, Chu Q, Crenshaw EB, 3rd, Kaestner KH, Bartolomei MS, Shulman GI, Birnbaum MJ (2001b) Insulin resistance and a diabetes mellitus-like syndrome in mice lacking the protein kinase Akt2 (PKB beta). Science 292:1728-1731.

Dulac C, Axel R (1995) A novel family of genes encoding putative pheromone receptors in mammals. Cell 83:195-206.

Easton RM, Cho H, Roovers K, Shineman DW, Mizrahi M, Forman MS, Lee VM, Szabolcs M, de Jong R, Oltersdorf T, Ludwig T, Efstratiadis A, Birnbaum MJ (2005) Role for Akt3/protein kinase Bgamma in attainment of normal brain size. Mol Cell Biol 25:1869-1878.

Garofalo RS, Orena SJ, Rafidi K, Torchia AJ, Stock JL, Hildebrandt AL, Coskran T, Black SC, Brees DJ, Wicks JR, McNeish JD, Coleman KG (2003) Severe diabetes, age-dependent loss of adipose tissue, and mild growth deficiency in mice lacking Akt2/PKB \{beta\}. J Clin Invest 112:197-208.

Hemmings BA (1997) Akt signaling: linking membrane events to life and death decisions. Science 275:628-630.

Jones PF, Jakubowicz T, Hemmings BA (1991a) Molecular cloning of a second form of rac protein kinase. Cell Regul 2:1001-1009.

Jones PF, Jakubowicz T, Pitossi FJ, Maurer F, Hemmings BA (1991b) Molecular cloning and identification of a serine/threonine protein kinase of the second-messenger subfamily. Proc Natl Acad Sci USA 88:4171-4175.

Kaldi I, Martin RE, Huang H, Brush RS, Morrison KA, Anderson RE (2003) Bright cyclic rearing protects albino mouse retina against acute lightinduced apoptosis. Mol Vis 9:337-344.

Kandel ES, Hay N (1999) The regulation and activities of the multifunctional serine/threonine kinase Akt/PKB. Exp Cell Res 253:210-229.

Khwaja A (1999) Akt is more than just a Bad kinase. Nature 401:33-34.

Kim AH, Yano H, Cho H, Meyer D, Monks B, Margolis B, Birnbaum MJ, Chao MV (2002) Aktl regulates a JNK scaffold during excitotoxic apoptosis. Neuron 35:697-709.

Krishnamoorthy RR, Crawford MJ, Chaturvedi MM, Jain SK, Aggarwal BB, Al-Ubaidi MR, Agarwal N (1999) Photo-oxidative stress downmodulates the activity of nuclear factor-kappaB via involvement of caspase-1, leading to apoptosis of photoreceptor cells. J Biol Chem 274:3734-3743.

LaVail MM, Unoki K, Yasumura D, Matthes MT, Yancopoulos GD, Steinberg RH (1992) Multiple growth factors, cytokines, and neurotrophins res- cue photoreceptors from the damaging effects of constant light. Proc Natl Acad Sci USA 89:11249-11253.

Lawlor MA, Alessi DR (2001) PKB/Akt: a key mediator of cell proliferation, survival and insulin responses? J Cell Sci 114:2903-2910.

Li F, Cao W, Anderson RE (2003) Alleviation of constant-light-induced photoreceptor degeneration by adaptation of adult albino rat to bright cyclic light. Invest Ophthalmol Vis Sci 44:4968-4975.

Masure S, Haefner B, Wesselink JJ, Hoefnagel E, Mortier E, Verhasselt P, Tuytelaars A, Gordon R, Richardson A (1999) Molecular cloning, expression and characterization of the human serine/threonine kinase Akt-3. Eur J Biochem 265:353-360.

Mora A, Sabio G, Gonzalez-Polo RA, Cuenda A, Alessi DR, Alonso JC, Fuentes JM, Soler G, Centeno F (2001) Lithium inhibits caspase 3 activation and dephosphorylation of PKB and GSK3 induced by $\mathrm{K}^{+}$deprivation in cerebellar granule cells. J Neurochem 78:199-206.

Muresan V, Joshi HC, Besharse JC (1993) Gamma-tubulin in differentiated cell types: localization in the vicinity of basal bodies in retinal photoreceptors and ciliated epithelia. J Cell Sci 104:1229-1237.

Nakatani K, Thompson DA, Barthel A, Sakaue H, Liu W, Weigel RJ, Roth RA (1999) Up-regulation of Akt3 in estrogen receptor-deficient breast cancers and androgen-independent prostate cancer lines. J Biol Chem 274:21528-21532.

Organisciak DT, Darrow RM, Barsalou L, Darrow RA, Kutty RK, Kutty G, Wiggert B (1998) Light history and age-related changes in retinal light damage. Invest Ophthalmol Vis Sci 39:1107-1116.

Orike N, Middleton G, Borthwick E, Buchman V, Cowen T, Davies AM (2001) Role of PI 3-kinase, Akt and Bcl-2-related proteins in sustaining the survival of neurotrophic factor-independent adult sympathetic neurons. J Cell Biol 154:995-1005.

Peng X-D, Xu P-Z, Chen M-L, Hahn-Windgassen A, Skeen J, Jacobs J, Sundararajan D, Chen WS, Crawford SE, Coleman KG, Hay N (2003) Dwarfism, impaired skin development, skeletal muscle atrophy, delayed bone development, and impeded adipogenesis in mice lacking Aktl and Akt2. Genes Dev 17:1352-1365.

Rajala RV, McClellan ME, Ash JD, Anderson RE (2002) In vivo regulation of phosphoinositide 3-kinase in retina through light-induced tyrosine phosphorylation of the insulin receptor beta-subunit. J Biol Chem 277:43319-43326.

Rajala RV, McClellan ME, Chan MD, Tsiokas L, Anderson RE (2004) Interaction of the retinal insulin receptor beta-subunit with the $\mathrm{p} 85$ subunit of phosphoinositide 3-kinase. Biochemistry 43:5637-5650.

Rapp LM, Smith SC (1992) Morphologic comparisons between rhodopsinmediated and short-wavelength classes of retinal light damage. Invest Ophthalmol Vis Sci 33:3367-3377.

Reiter CE, Sandirasegarane L, Wolpert EB, Klinger M, Simpson IA, Barber AJ, Antonetti DA, Kester M, Gardner TW (2003) Characterization of insulin signaling in rat retina in vivo and ex vivo. Am J Physiol Endocrinol Metab 285:E763-E774.

Samardzija M, Wenzel A, Aufenberg S, Thiersch M, Rem C, Grimm C (2006) Differential role of Jak-STAT signaling in retinal degenerations. FASEB J 20:2411-2413.

Sanvicens N, Gomez-Vicente V, Masip I, Messeguer A, Cotter TG (2004) Oxidative stress-induced apoptosis in retinal photoreceptor cells is mediated by calpains and caspases and blocked by the oxygen radical scavenger CR-6. J Biol Chem 279:39268-39278.

Scheid MP, Woodgett JR (2001) PKB/AKT: functional insights from genetic models. Nat Rev Mol Cell Biol 2:760-768.

Tschopp O, Yang Z-Z, Brodbeck D, Dummler BA, Hemmings-Mieszczak M, Watanabe T, Michaelis T, Frahm J, Hemmings BA (2005) Essential role of protein kinase $\mathrm{B}\{$ gamma\} ( $\mathrm{PKB}\{$ gamma $/ \mathrm{Akt} 3$ ) in postnatal brain development but not in glucose homeostasis. Development 132:2943-2954.

Wahlin KJ, Lim L, Grice EA, Campochiaro PA, Zack DJ, Adler R (2004) A method for analysis of gene expression in isolated mouse photoreceptor and Muller cells. Mol Vis 10:366-375.

Yang ZZ, Tschopp O, Hemmings-Mieszczak M, Feng J, Brodbeck D, Perentes E, Hemmings BA (2003) Protein kinase B alpha/Akt1 regulates placental development and fetal growth. J Biol Chem 278:32124-32131.

Zheng L, Anderson RE, Agbaga MP, Rucker III EB, Le YZ (2006) Loss of BCL-XL in rod photoreceptors: increased susceptibility to bright light stress. Invest Ophthalmol Vis Sci 47:5583-5589. 